\title{
An unusual presentation of methanol poisoning
}

\author{
Suha Turkmen, Umut Eryigit*, Aynur Sahin, Seda Mentese, Abdulkadir Gunduz \\ Department of Emergency Medicine, Faculty of Medicine, Karadeniz Technical University, Trabzon, Turkey
}

\section{ARTICLE INFO}

\section{Article History}

Received $\quad 29 / 06 / 2013$

Accepted $\quad 23 / 08 / 2013$

\section{* Correspondence to:}

Umut Eryigit

Department of Emergency Medicine,

Faculty of Medicine,

Karadeniz Technical University,

Trabzon, Turkey

email: umuteryigitacil@gmail.com

\section{ABSTRACT}

Methanol is a substance possessing high toxicity even in small quantities. It may lead to intracerebral hemorrhage, blindness and death. Methanol poisoning generally takes place as result of oral ingestion, but may rarely occur through inhalation or transdermally. Persons may be exposed to methanol because of illegal alcohol beverage producers or alternative medicine providers. A 55-year-old male with methanol poisoning as a result of rubbing a self-prepared mixture of methylated spirit and aspirin on his shoulder with the aim of alleviating pain was described in this case report. Emergency physicians should remember that patients presenting with visual problems, altered awareness and impaired balance may have methanol poisoning.

J. Exp.Clin.Med., 2013; 30:367-368

\section{Keywords:}

Accidental

Methanol

Poisoning

Transdermal

\section{Introduction}

Methanol is generally used as an industrial solvent (Jammalamadaka and Raissi, 2010). Poisoning may take place accidentally or for purposes of suicide or as a result of ingestion by alcoholics who think it resembles the taste and smell of ethyl alcohol. It generally arises as a result of oral ingestion, though poisoning by inhalation and transdermally have also been reported (Onder et al, 1999; Karaduman et al, 2009). This report describes a case of transdermal methanol poisoning in a patient who rubbed a mixture of blue spirit and aspirin he had prepared himself to relieve shoulder pain onto his shoulder and also poured it onto some cotton and placed this on the shoulder region.

\section{Case}

A 55-year-old male woke up in the morning with double vision, impaired balance and confusion and was brought to public hospital. He had a Glasgow Coma Scale (GCS) score of 13. Brain tomography performed on suspicion of a cerebrovascular event was normal. The patient's history revealed long-term shoulder pain. He denied any medication and history of illness. Following a friend's advice he had rubbed a mixture of methylated spirit and aspirin that he had prepared the evening before onto his shoulder during the night. He had also poured part of the mixture onto some cotton and placed this on the shoulder region. Methanol poisoning was then suspected; $20 \%$ ethyl alcohol at $0.6 \mathrm{~g} /$ $\mathrm{kg}$ was administered via nasogastric tube and the patient was transferred to our emergency department. He was confused when he arrived, with a GCS score of 13 (E3, V4, M6). Vital findings revealed arterial tension of $140 / 83 \mathrm{mmHg}$, pulse 64/ min, respiration rate $18 / \mathrm{min}$, temperature $35.8^{\circ} \mathrm{C}$, and oxygen saturation of $99 \%$. Light reflex was bilaterally positive, pupils were normal. Bilateral horizontal nystagmus was present. Strength examination was normal. Fingertip blood sugar was $115 \mathrm{mg} / \mathrm{dL}$. Physical examination revealed erythema of the 
skin, more pronounced on the upper part of the body. Routine biochemical investigation revealed blood urea nitrogen (BUN) $18 \mathrm{mg} / \mathrm{dL}$, creatinine $0.9 \mathrm{mg} / \mathrm{dL}$, sodium $139 \mathrm{mmol} / \mathrm{L}$, potassium $4.5 \mathrm{mmol} / \mathrm{L}$, and chlorine $104 \mathrm{mmol} / \mathrm{L}$. Arterial blood gas analysis yielded a $\mathrm{pH}$ value of 7.43 , a partial carbon dioxide pressure $\left(\mathrm{PCO}_{2}\right)$ of $43.4 \mathrm{mmHg}$, a partial oxygen pressure $\left(\mathrm{PO}_{2}\right)$ of $76 \mathrm{mmHg}$, a $\mathrm{HCO}_{3}$ concentration of 29 $\mathrm{mEq} / \mathrm{L}$, and an oxygen saturation of $99.3 \%$. Blood methanol level was $51 \mathrm{mg} / \mathrm{dL}$. Ethyl alcohol $(0.11 \mathrm{mg} / \mathrm{kg})$ administered nasogastrically was maintained as maintenance treatment. Hemodialysis was not performed, since the patient's double vision and awareness levels stabilized in the early stage. The patient was discharged with full recovery after $72 \mathrm{~h}$ of observation.

\section{Discussion}

Methanol is a colorless form of alcohol and soluble in water. Methanol is oxidized to formaldehyde with the enzyme alcohol dehydrogenase, and formaldehyde to formic acid with the enzyme formaldehyde dehydrogenase. It is these metabolites of methanol that are held responsible in poisoning. In particular, formic acid leads to metabolic acidosis and tissue damage by causing greater cytochrome p-450 inhibition (Verslegers and De Deyn, 2006). The lethal dose for methanol is $1-2 \mathrm{ml} / \mathrm{kg}$ (Jammalamadaka and Raissi., 2010). But temporary blindness and death have been reported with doses as low as $0.1 \mathrm{ml} / \mathrm{kg}$ (Jammalamadaka and Raissi, 2010). Visual problems such as double vision, blurred vision, reduced vision, impaired light reflex, photophobia and blindness may be observed in poisoning cases. These problems are temporary in the majority of cases, and permanent eyesight problems develop in only 25\%$33 \%$ of cases (Karaduman et al., 2009). Poisoning can lead to symptoms involving the gastrointestinal system, such as nausea, vomiting and stomachache, and to others involving the central nervous system, such as headache, seizure, stupor, coma, cerebral hemorrhage, diffuse cerebral edema, cerebellar lesions or optic nerve lesions (Karaduman et al., 2009).

The basic aim in treatment is to stabilize metabolic acidosis, prevent the oxidation of methanol to toxic metabolites, and to remove methanol and formic acid. Alkalization, folic acid support, oral or intravenous ethanol, fomepizole and hemodialysis are administered for the purpose (Sutton et al., 2002). Fomepizole recommended dosing is 15 $\mathrm{mg} / \mathrm{kg}$ intravenous (IV) loading, followed by $10 \mathrm{mg} / \mathrm{kg}$ IV every 12 hours four times (Bestic et al., 2009). The ethanol administration is $10 \mathrm{ml} / \mathrm{kg}$ IV loading followed by $1.5 \mathrm{ml} / \mathrm{kg}$ and IV solution should be 10 percent ethanol (Berk, 2004).

Methanol is a relatively cheap and easily obtained form of alcohol with a wide range of uses. Therefore alcohol addicts get easily and illegal producers put in the alcoholic beverages instead of ethanol. Poisoning usually arises as a result of oral ingestion. Although there is no difficulty in the diagnosis of poisoning through oral ingestion, cases of inhalation or transdermal poisoning do pose diagnostic difficulties. Emergency physicians should remember that patients presenting with visual problems, altered awareness and impaired balance may have methanol poisoning. It must not be forgotten that in addition to oral exposure, transdermal or inhalation exposure may also cause high mortality and morbidity.

\section{REFERENCES}

Berk, W.A., 2004. Alcohols. In: Tintinalli, J.E., Kelen, G.D., Stapczynski, J.S., editors. Emergency Medicine. A Comprehensive Study Guide. $6^{\text {th }}$ ed. New York: McGraw Hill. 1067-1069.

Bestic, M., Blackford, M., Reed, M., 2009. Fomepizole: A critical assessment of current dosing recommendations. J. Clin. Pharmacol. 49, 130137.

Jammalamadaka, D., Raissi, S., 2010. Ethylene glycol, methanol and isopropyl alcohol intoxication. Am. J. Med. Sci. 339, $276-81$.

Karaduman, F., Asil, T., Balci, K., Temizoz, O., Unlu, E., Y1lmaz, A., Utku, U., 2009. Bilateral basal ganglionic lesions due to transdermal methanol intoxication. J. Clin. Neurosci. 16, 1504-1506.

Onder, F., Ilker, S., Kansu, T., Tatar, T., Kural, G., 1999. Acute blindness and putaminal necrosis in methanol intoxication. Int. Ophthalmol. 22, 81-84.

Sutton, T.L., Foster, R.L., Liner, S.R., 2002. Acute methanol ingestion. Pediatr. Emerg. Care. 18, 360-363.

Verslegers, W.R., De Deyn, P.P., 2006. Serious intoxication after inhaling methanol. Ned Tijdschr. Geneeskd. 16, 2057. 